\section{Abstractions}

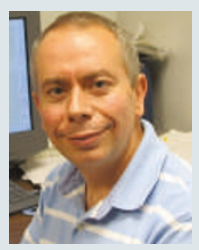

MAKING THE PAPER

\author{
Tim Wright
}

\section{A huge rupture, detected in satellite data, leads to a gruelling camel trek.}

The radar carried by the European Space Agency's Envisat satellite, which was launched in 2002, was designed to measure and map Europe's atmosphere, ocean and land - not to monitor earthquakes. But earthquake scientists, lacking other options, have appropriated such satellites for their own purposes. Last autumn, one research group was rewarded for its improvisation with startling data on a rarely seen tectonic phenomenon. The researchers' careful observation, combined with good fortune, earned them a trip to one of the hottest places on the planet.

On page 291 of this issue, Tim Wright, an Earth scientist at the University of Leeds, UK, and his colleagues detail the phenomenon. Over the course of about a week, a 60-kilometre-long section of a rift, located in Afar, Ethiopia, opened up by as much 8 metres. Molten rock percolated to the surface, pushing apart two tectonic plates. It's the largest magma-induced rupture ever examined with modern satellite technology. Such a splitting happens more often under water, where radar satellites cannot see, and where measurements are difficult and expensive to obtain.

When Atalay Ayele, a seismologist at Addis Ababa University, noticed 163 small earthquakes near Afar's Dabbahu dyke over the course of about 3 weeks, he contacted Cindy Ebinger, a geologist at the University of London's Royal Holloway, who, in turn, asked Wright to take a look at what Envisat might have detected. Wright was not expecting anything unusual. "We got the biggest deformation signal we've ever measured," Wright says. "It was absolutely extraordinary."

In January 2006, Wright and his colleagues set out on a gruelling 3-week expedition to the scorching desert of Afar. Their mission: to install 10 continuously recording global

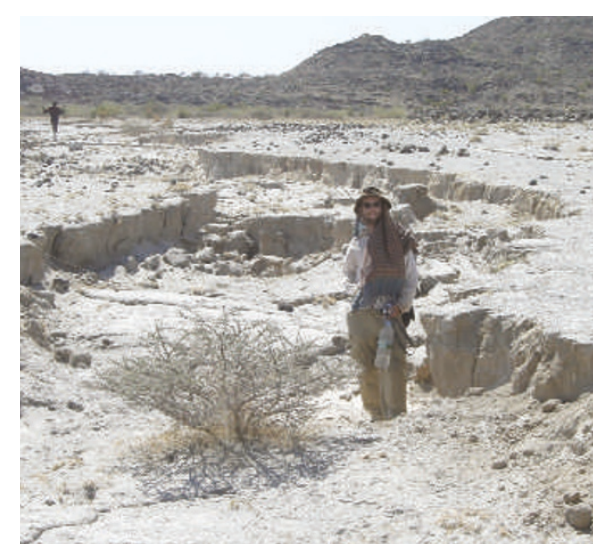

positioning instruments around the rift to measure the rapid ground motion resulting from the initial earthquakes.

The trip was not easy. After driving to within 20 kilometres of the rift by car, the researchers continued on foot and by camel. The Afari government, local tribal chiefs, and two sets of translators helped them reach the rift and negotiate an agreement to have local inhabitants guard their scientific instruments.

According to Wright, the data suggest that, in general, magma controls the rifting in the late stages of continental splitting. This rupture sets up stresses that Wright and his colleagues continue to monitor. "We now have a unique and timely opportunity to learn about Earth's physical properties, how magma moves through the crust and mantle, and how the crust grows at divergent plate boundaries," Wright says.

Wright would like to see NASA or the European Space Agency launch a new satellite that is specially designed to study earthquakes and volcanoes. That would lessen the dependence on ground-based instruments - as well as the camel treks sometimes necessary to install them. Longer-wavelength radar would do a better job of peering through vegetation. And better estimates of satellite orbits would allow geologists to measure motion in millimetres rather than centimetres. "We'd be able to see how the plates are moving and how the strain is building up before earthquakes and eruptions," says Wright.
What was different from what the conventional idea would have shown? If proteins have to cross an energy barrier when they fold, the making of all the bonds that hold the atoms in their folded position would occur simultaneously, and therefore all atomic unfolding behaviours would be identical. What we saw is that pairs of atoms make bonds almost independently of the rest of the protein. It is the consolidation of the whole network of bonds that acts as a web, holding the folded structure together.

\section{What's next?}

We are developing theoretical predictions to determine which proteins show these properties. Small and helical proteins are more likely to conform to this type of behaviour, but we may find it is more ubiquitous than previously thought.

\title{
QUANTIFIED CROSSREF
}

\section{A numerical perspective on CrossRef.}

In 2000, the world's leading scholarly publications formed an association to provide citation linking between peerreviewed publications. It holds no full-text content, but rather offers online linking through digital object identifiers (DOIs). Using these numerical tags allows users to click from one citation to another. CrossRef gets around the open-access debate by linking only to citations. If users have access to those publications they can then access the article's full text. Nature Publishing Group (NPG) helped found CrossRef, and deposited CrossRef links to Nature in 2000. In 2001, NPG added 13 research and reviews journals, 28 specialist journals and several reference resources. Last month CrossRef released data showing how the network has grown and has been used.
1,657 is the number of publishers and societies participating in CrossRef

$65 \%$ is the proportion of non-profit publishers who have joined CrossRef.

1,066 is the number of libraries participating in CrossRef.

21,744,529 DOls have been registered so far.

14,855 is the number of journals included in CrossRef. 